\title{
Donor Advocacy with Special Reference to Belgium
}

\author{
J.P. Squifflet
}

\begin{abstract}
Before any published Belgian law, EU Directive, and/or EU Action Plan, the donor advocate was naturally a member of the transplantation team performing living kidney donation. The need of donor advocacy appeared obvious with liver living donation, which was and is still a risky procedure. Today, it is clear that the donor advocacy must not be limited to living donation but extended to brain-dead and cardiac-dead donation. Nevertheless, its complexity will need experienced persons in the field of organ donation as well as transplantation, while remembering that patients' first right is the right to donate.
\end{abstract}

$\mathbf{T}$ he gap between donor organ availability and the demand for transplantation is large (Fig 1) and increasing all over the world. In 2010, the number of patients awaiting renal transplantation in Belgium was 866 on January 1, 2010 and 914 on December 31, 2010. During the same year, 408 candidates (20\%) were transplanted with either a donor after brain death (DBD) or a donor after cardiac death (DCD) kidney ${ }^{1}$ and 49 with a living-donor graft (related or unrelated); as many as 28 Belgian patients died on the Eurotransplant waiting list in 2009. ${ }^{1}$ Indeed, the magnitude of the disparity between donation and recipient need has prompted the increased use of living donors. ${ }^{2}$

During 2010, clearly, not all Belgian potential donors progressed to organ procurement despite a low family refusal rate. Overall, $>85 \%$ of families approached agree to proceed. ${ }^{1}$ Factors influencing the family's perception of the donor process are numerous and include the difficulty regarding the health care team's change in focus from the death of their family member to the health of an unseen patient at some other location and worries regarding the appearance of their loved one after donation. Many of these and other issues are addressed by the transplantation community.

Faced with the drive to help ill patients through transplantation by shrinking the gap between organ availability and need, the importance of protecting the rights of living and deceased donors has been emphasized. ${ }^{3}$ It is in this climate that donor advocacy has evolved to keep the health care team focused on the protection and the rights of any person or family to donate for the good of another. ${ }^{3}$

\section{DEFINITION OF DONOR ADVOCACY}

Donor advocacy may be defined as "a process or instance of supporting a potential or actual organ donor." ${ }^{3}$ That pro- cess or instance protects the donor's right to donate; it creates a representation for the donor in the decisionmaking process that occurs as part of transplantation evaluation and completion. ${ }^{3}$ Therefore, this broad definition extends to every kind of donation, whether deceased or living.

Donor advocacy is not the role of devil" advocate, a false attitude that has grown up around the field of living donation. Indeed, world and/or local regulations sometimes require transplant programs to appoint an independent advocacy team to evaluate, educate, and consent to all potential living donors as part of the transplantation progress. But strict regulations only apply for living liver donors (or extrarenal organs), the background behind such legislation being well known. ${ }^{4}$ Although the broad term "donor advocacy" applies to advocacy for all donors, it is important to realize it is most commonly associated with living donation, especially liver living donation, but need not be confined to it.

\section{ETHICS AND LEGAL ATTITUDES}

A first step towards donor advocacy came with the Amsterdam Forum on care of the live kidney donor. ${ }^{5-7}$ Forum participants affirmed the necessity for live donors to receive complete medical and psychosocial evaluation before donation. They elaborated in detail acceptance limits of donor hypertension, obesity, dyslipidemia, renal function, urine

From the Department of Abdominal Surgery and Transplantation, CHU Sart Tilman, Liège, Belgium.

Address reprint requests to Pr. Jean-Paul Squifflet, Department of Abdominal Surgery and Transplantation, $\mathrm{CHU}$ Sart Tilman, B35, 4000 Liège, Belgium. E-mail: jean-paul.squifflet@ chir-transplantation.be

(C) 2011 by Elsevier Inc. All rights reserved. 360 Park Avenue South, New York, NY 10010-1710 


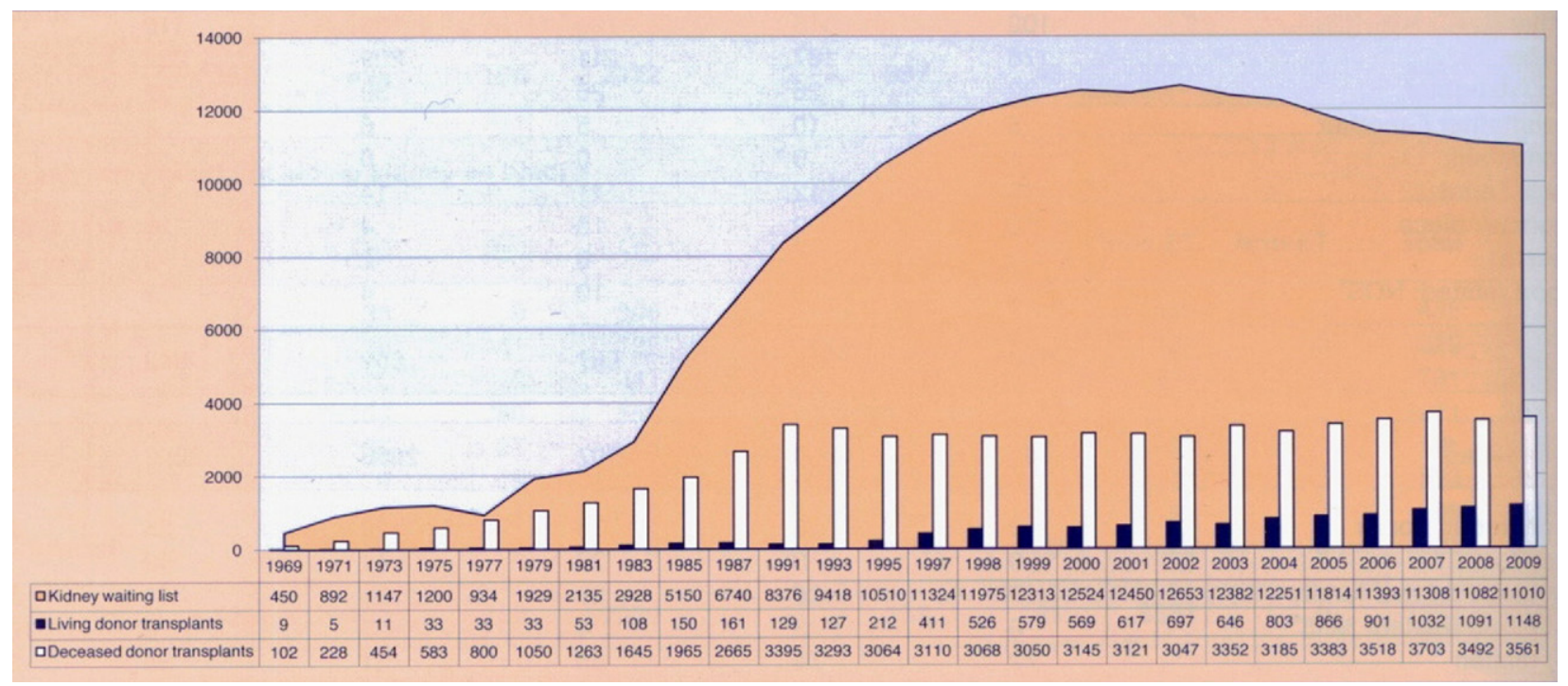

Fig 1. Dynamics of the Eurotransplant kidney transplant waiting list and transplants between 1969 and 2009.

protein and blood, stone disease, and historical malignancy that still permit live kidney donation. A great detail of discussion focused on prevention of transmittable infectious diseases through live kidney transplantation. Specific recommendations for screening of various viral, bacterial, and parasitic diseases were presented as were pre- and postoperative donor issues. ${ }^{5}$

In view of these evolving trends in living-donor transplantation, and the need for using marginal or extended-criteria living donors, the Ethics Committee of the Transplantation Society proposed several recommendations, including a donor advocate:" "To minimize the appearance of a 'conflict of interest,' transplant centers should make efforts to ensure that the medical and psychosocial assessments and the decision to donate incorporates health care profession$\mathrm{al}(\mathrm{s})$ not involved in the care of the recipient. The intent of this recommendation is to provide a health care professional advocating for the welfare of the potential donor. Procedural safeguards should be used and explored to minimize coercion and enhance autonomous decision making, for example, by a 'cooling off period' and assessment of donor retention of information."

A second step was undertaken at the Vancouver Forum. ${ }^{8}$ Emerging data pertaining to the aggregate risks and benefits of live lung, liver, pancreas, and intestine transplantation provided more information regarding the factors that enter into the ethical decision to place a healthy person in harms' way. ${ }^{8}$ The limited availability of information about outcomes for the donors and recipients mandated that live lung, liver, pancreas, and intestine organ donation and transplantation must proceed with thoughtful independent oversight and transparency. Because organs recovered from deceased donors offer substantial (and sometimes superior) benefits to potential recipients, with no risk to a healthy live donor, efforts to maximize the use of organs from deceased donors must not be impeded by the development of live organ donation.

Therefore, a consensus statement came from the deliberations of the Ethics Group of the Vancouver Forum ${ }^{9}$ defining responsibilities of the transplant team performing all kinds of living donation. ${ }^{9}$ They must implement procedural safeguards to enhance donor understanding, safety, and autonomous decision making. These were considered to be essential to the process of live organ donation, particularly for live lung, liver, pancreas, and intestine donors.

The essential procedural components included:

Inclusion of health care professionals in the donation process who are exclusively responsible for the donor's evaluation and welfare. Such an individual should not have direct contact with the recipient or be overtly influenced by concerns for the recipient.

Repetition of the information pertaining to live donation, in recognition that informed consent is a process, not an event.

Psychosocial evaluation, to include the capacity of the donor to process information and give informed consent.

Additional safeguards may include:

Reflection period after medical acceptance and decision to donate.

Assessment of donor retention of information and understanding.

External review committees, ie, donor advocacy.

A final ethical step came with the Declaration of Istanbul on Organ Trafficking and Transplant Tourism. ${ }^{10}$ To ensure the protection and safety of living donors and appropriate recognition for their heroic act while combating transplant tourism, organ trafficking, and transplant commercialism, several strategies were suggested: among them, the deter- 
mination of the medical and psychosocial suitability of the living donor, as guided by the recommendations of the Amsterdam and Vancouver Forums. It is emphasized that all donors should undergo psychosocial evaluation by mental health professionals during screening, and that psychosocial service should be offered as a standard component of follow-up. ${ }^{10}$

Thus the potential for coercion, lack of respect for patient autonomy, and perception of incompleteness of informed consent throughout medicine and specifically in the field of transplantation were identified. The purpose of establishing donor advocacy paradigms and infrastructure was the consequence of addressing such abuse potential.

The legal aspect in European Directive 210/45/EU ${ }^{11}$ pertains to standards of quality and safety of human organs intended for transplantation. Therefore donor protection, selection, and evaluation rules are based only on quality and safety aspects of living donation. Action Plan 2009-2015 ${ }^{12}$ aims to promote altruistic donation programs and the development of registration practices regarding living donors to assess and guarantee their safety. The Commission will also help to develop adequate tools to facilitate the proper collection of information on the medical, psychosocial, financial, and social consequences of a living donation, in the short and the long term. This information, coupled with the exchange of best practices on living donation programs among the member states, should help to develop evidence-based guidelines and consensus documents, and address the selection, evaluation, and follow-up of the living donor. Registers of living donors should be established to facilitate monitoring and follow-up. ${ }^{12}$

In Belgium, the act on organ donation and transplantation (June 13, 1986) ${ }^{13}$ was modified by an act of February $25,2007,{ }^{14}$ which address the advocacy team in article 5 (original article 8 bis): "Any procurement from living donors must be submitted to preliminary multidisciplinary consultation" (in French: Tout prélèvement sur des personnes vivantes doit faire l'objet d'une concertation pluridisciplinaire préalable"). So far, application modalities are not yet defined but could lead to a restrictive approach of the donor advocacy role.

\section{DONOR ADVOCACY AND THE DECEASED DONOR}

In Belgium, the law on organ donation and transplantation based on the presumed consent principle (opting-out system) is not sufficient authority allowing the removal of organs after death except for those who made a positive declaration at the national registry during their life. For those who did not make any decision during their life, even if they are presumed to be in favor of organ donation, patient rights law, transparency, and common sense require informing family members. In these circumstances, experience confirms that the family's collective emotion is often not unified. Indeed the refusal rate was as much as $15 \%$ in 2009. ${ }^{1}$
Here, again, the donor advocate could be of great use in the process. An advocacy team may play a central role in discussing with the family the donor's willingness and capacity to donate as indicated by the Belgian law. Its role could be more accurate with the development of organ procurement in DCD. The advocacy team may also help to keep the focus on the donor's rights. The team may continue to answer the family's questions as the time to donation proceeds.

There are also situations where staff attitudes may benefit from the assistance of a donor advocacy team. Indeed, it is important to keep in mind that staff may have strong feelings of distress regarding the procurement process, especially for DCD. The advocacy team may take the time to provide in-services, material, and resources to indicate the true nature of a donor's choice. That last role is of particular interest in Belgium with organ procurement after euthanasia.

\section{DONOR ADVOCACY AND THE LIVING DONOR}

Based on the ethical guidelines of the Amsterdam and Vancouver Forums, the Declaration of Istanbul, the European Directive and Action Plan, and Belgian acts, the donor advocate holds a particularly important job. It includes:

- Advising the donor of the risks of the procedure.

- Avoiding pressuring the potential donor to consent to the gift.

- Ensuring more complete donor information in the difficult climate left by minimal precedent.

- Creating true informed consent in a time of what is often family crisis.

- Exploring donors' questions, feelings, and motivation regarding the decision.

- Explaining, to patients who are eligible to donate, specified and unspecified donation and direct and indirect donation. $^{15}$

- Serving as a useful contact for further discussion with family.

- Helping to improve variables such as medical mistrust, bodily integrity, and religiosity.

Donor advocacy, when independent of transplantation staff, more optimally avoids a potential conflict of interest. Moreover, many argue that ethical issues related to simultaneous involvement with both donors and recipients, in addition to a need to ensure confidentiality, is another supporting cause for the provision of separate care providers for donors and recipients.

\section{DONOR ADVOCACY AND THE FUTURE}

Living-donor transplantation started in Belgium before any Belgian acts or EU directives/action plans and without donor advocacy. All living-donor kidney recipient pairs were referred by local nephrologists to the transplant center team. The latter included nephrologists, transplant surgeons, coordinators, nursing staffs, and psychologists on 
request. Throughout the process until the day of transplantation, information was given to all pairs through leaflets, booklets, websites, consultations, and good sense practice. The aim was to assure quality and safety, assess the freedom of the act, and avoid coercion. Strict criteria for living donor selection were applied, and today, data confirm that kidney donor life expectancy is still greater compared with the general population. All kidney transplant candidates, who could not get a live-donor graft, were put on the Eurotransplant cadaver waiting list.

Owing to the fact that DBD and DCD rates cannot be increased and the quality of grafted organs is decreasing, there is a need to use more marginal donors and relax the selective criteria for living donation. Meanwhile, living liver donation was proposed to spare DCD liver grafts for recipients who could not fulfil the usual criteria for transplantation. Indeed living liver donation is a more risky procedure compared with living kidney donation, with increased morbidity and mortality. Moreover, due to emergency situations, the decision to donate must be undertaken within a few hours without any cooling off period or information brought by the transplantation team. Therefore, it became obvious that in these circumstances there is a need for a donor advocate who could preserve the donor's rights and help in the decision making. Is there a need to extend the role of the living liver donor advocate? If the answer is positive, its role should be extended to not only living kidney donor advocate, but also to DBD and DCD, for the above reasons. If the answer is negative, or its role restricted to living donor advocacy, it should not be a role of devil's advocate. Increasingly often, all transplant teams are confronted with physicians who have no experience in transplantation and donation, who do not themselves want to donate, and who display wrong information regarding donation and organ transplantation. These physicians, besides wrongly extending living liver donation risks to kidney living donation, are not sensitive to donor rights, which includes the right to donate. Therefore, and for that last reason, those physicians must be separate from the donor advocacy role.

The last question is whether that role should be undertaken by a psychologist or a psychiatrist in all circumstances. It is good sense that close family members are not willing to receive help from such persons when they want to save children or relatives. By contrast, their help could be valuable for a potential living donor with undirected unspecified wishes of donation, the so-called "bon samaritain." In that situation, they will share the donor advocacy role with the transplantation team.

The donor advocacy role must extend to all kinds of living and DBD/DCD donation. Its complexity means that it will be undertaken by experienced persons in the field of donation as well as transplantation, while always remembering that the first donor right is the right to donate.

Kahlil Gibran, wrote about donation in The Prophet ${ }^{16}$ : "Then said a rich man, 'Speak to us of Giving.' ... See first that you yourself deserve to be a giver, and an instrument of giving. For in truth it is life that gives unto life-while you, who deem yourself a giver, are but a witness. And you receivers-and you are all receivers-assume no weight of gratitude, lest you lay a yoke upon yourself and upon him who gives."

\section{REFERENCES}

1. Detry O, Troisi R: Organ Donation in Belgium 2009: 20\% of donation after cardiocirculatory death Transplant Proc 42:4365, 2010

2. Squifflet JP: The history of kidney transplantation: past, present and future with special references to the Belgian history. In: Kidney transplantation, vol 2. Croatia: Intech Open Access Publisher;2011

3. Kashmer DM, Schmitt T, Brayman K: Donor advocacy. In Gruessner RWG, Benedetti E (eds): Living donor organ transplantation. USA: McGraw-Hill; 2008, p 54

4. Rudow DL, Brown RS: Role of the independent donor advocacy team in ethical decision making. Prog Transplant 15:298, 2005

5. Monaco AP, Morris PJ: Care of the live kidney donor: consensus on the ultimate gift. Transplantation 79(s2):51, 2005

6. Amsterdan Forum: A report of the Amsterdam Forum on the care of the life kidney donor: data and medical guidelines. Transplantation 79(s2):53, 2005

7. Consensus Statement of the Amsterdam Forum on the Care of the Live Kidney Donor. Transplantation 78:491, 2004

8. Barr ML, Belghiti J, Villamil FG, et al: A report of the Vancouver Forum on the Care of the Live Organ Donor: lung, liver, pancreas, and intestine data and medical guidelines. Transplantation 81:1373, 2006

9. Pruett TL, Tibell A, Alabdulkareem A, et al: The ethics statement of the Vancouver Forum on the Live Lung, Liver, Pancreas, and Intestine Donor. Transplantation 81:1386, 2006

10. Declaration of Istanbul on Organ Trafficking and Transplant Tourism. Available at http://www.declarationofstanbul.org

11. Dir (UE) $n^{\circ} 2010 / 53 /$ UE of the European Parliament of the Council of 7 July 2010 on standards of quality and safety of human organs intended for transplantation, J.O.U.E., L. 207, 6 August 2010, p. 14

12. Communication from the Commission, Action Plan on Organ Donation and Transplantation (2009-2015): Strengthened cooperation between member stares, COM (2008) 819 final

13. Loi du 13 juin 1986 sur le prélèvement et la transplantation d'organes, M.B., 14 février 1987, p 2129

14. Loi du 25 février 2007 modifiant la loi du 13 juin 1986 sur le prélèvement et la transplantation d'organes, M.B., 13 avril 2007, p 20409

15. Dor FJM, Massey EK, Frunza M, et al: New classification of ELPAT for living organ donation. Transplantation 91:935, 2011

16. Gibran K: The Prophet 